Carnets de géographes

GÉOGRAPHES

\title{
La favela Vila Autódromo : façonnement et délitement d'un haut lieu de la résistance urbaine à Rio de Janeiro
}

\section{Margaux De Barros}

\section{(2) OpenEdition}

Journals

Electronic version

URL: https://journals.openedition.org/cdg/4988

DOI: $10.4000 /$ cdg. 4988

ISSN: 2107-7266

Publisher

UMR 245 - CESSMA

Electronic reference

Margaux De Barros, "La favela Vila Autódromo : façonnement et délitement d'un haut lieu de la résistance urbaine à Rio de Janeiro", Carnets de géographes [Online], 12 | 2019, Online since 10 December 2019, connection on 21 September 2021. URL: http://journals.openedition.org/cdg/4988; DOl: https://doi.org/10.4000/cdg.4988

This text was automatically generated on 21 September 2021.

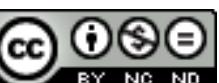

La revue Carnets de géographes est mise à disposition selon les termes de la Licence Creative Commons Attribution - Pas d'Utilisation Commerciale - Pas de Modification 4.0 International. 


\title{
La favela Vila Autódromo : façonnement et délitement d'un haut lieu de la résistance urbaine à Rio de Janeiro
}

\author{
Margaux De Barros
}

À Rio de Janeiro, l'organisation de la Coupe du monde masculine de football de 2014 et des Jeux Olympiques de 2016 a réactivé des opérations d'éviction massive de populations vivant dans les nombreux quartiers d'habitat précaire de la ville. De telles pratiques, appliquées de manière systématique tout au long des réformes urbaines qui ont marqué l'histoire de l'urbanisme de Rio depuis le début du 20e siècle (Abreu, 1988; Valladares, 2006) avaient pourtant été écartées des modes opératoires municipaux depuis le retour du pays à la démocratie et, de manière plus marquée encore, sous l'influence des injonctions de la Banque mondiale à privilégier réhabilitation et relogement in situ dans le cadre de dispositifs de rénovation. Comme dans de nombreuses autres villes du monde, notamment dans le contexte de la mise aux normes de l'espace urbain en vue de l'organisation de grands événements mondiaux, les politiques d'éradication des favelas refont ainsi surface. Menées à bien sous le mandat du maire Eduardo Paes (janvier 2009-janvier 2017), elles visent à transformer certains espaces afin d'accroître leur attractivité. Légitimées par un discours relatif à la revitalisation urbaine, elles dissimulent une mise à l'écart des populations socialement les plus fragiles, reléguées à la périphérie de la ville, tendant à moyen terme à transformer la composition sociale des quartiers et à accentuer la ségrégation résidentielle. Si un tel phénomène partage nombre de traits avec ceux observés dans d'autres métropoles, nords et suds confondus, il revêt des formes et une intensité particulières à Rio de Janeiro, où les inégalités sociales sont très marquées et les pratiques de l'État en direction des quartiers pauvres historiquement brutales et répressives 
2 Un des objectifs principaux de l'organisation des Jo est de stimuler le quartier Barra da Tijuca pour en faire une nouvelle centralité (Observatório das Metrópoles, 2015). Depuis les années 1970, ce « lieu de ségrégation par excellence » (Souza, 2001) s'est transformé en refuge pour les franges aisées. Situé dans la partie ouest de la ville, il fut créé ex nihilo sur des terres marécageuses pour devenir un espace moderne et rationnalisé, en opposition au reste de la ville. Le quartier est toutefois fragmenté : parallèlement au phénomène d'auto-ségrégation des classes moyennes et supérieures (Santos Maia, 1998), les favelas s'y développent dès les années 70. Caractérisées par l'informalité, le manque d'infrastructures et la précarité de l'habitat, elles représentent $26 \%$ des habitants de la subprefeitura Barra da Tijuca-Jacarepaguá1. Ses habitants constituent la main d'œuvre principale des constructions du quartier.

3 Marqué par une croissance rapide, mais aussi l'enclavement, le quartier est depuis peu articulé autour d'un couloir de bus $\mathrm{BRT}^{2}$ et d'un axe routier bordé par plusieurs centres d'affaires et de nombreux parcs de logements constitués de hautes tours blanches pour la plupart des condominios fechados, espaces d'entre-soi fermés avec surveillance et accès privés. Le développement urbain en cours à Barra da Tijuca se traduit par un processus «d'accumulation par dépossession » (Harvey 2011), le transfert d'actifs immobiliers passant des mains des plus défavorisés aux classes aisées et la marchandisation de services urbains bénéficiant seulement à ces dernières ${ }^{3}$. La valorisation immobilière et les expulsions engagées par la municipalité visent alors à encourager l'implantation des classes supérieures (Faulhaber, 2013; Santos Junior, Ramos Novaes, 2017).

4 Selon Lucas Faulhaber, à l'échelle de Rio de Janeiro, près de 67000 personnes ont été concernées par le processus de déplacements de population (2013). Les évictions sont menées à bien essentiellement dans le nord et l'ouest de la ville. A l'Ouest les quartiers Barra da Tijuca et Recreio concentrent 26\% des déplacements de population (Brum, 2013).

5 En recourant aux expulsions et dans certains cas à la gentrification ${ }^{4}$, les pouvoirs publics accentuent la ségrégation et donnent la priorité aux espaces dont les populations sont favorisées, excluant celles considérées comme déviantes ${ }^{5}$ (Goirand, 2001; Dahlet, 2016 ; Brum, 2013). Façonnée à partir de son appartenance sociale et ethnique, la figure du favelado, marginalisée à la fois socialement et politiquement (Goirand, 1991), ne répond pas aux injonctions sociales et économiques du paradigme de la ville marchande. Les favelas, espaces à connotation péjorative, sont considérées par les pouvoirs publics et les classes moyennes et supérieures comme des territoires pauvres, sous-investis par l'État et dominés par la violence (Brum, 2012; Machado, 2010). Alors qu'après le retour à la démocratie en 1985, les mouvements sociaux déclinent dans ces quartiers (Souza, 2006) et sont dominés par des logiques associatives favorisant "un contrôle négocié » (Machado, 2010) avec l'État, les déplacements de population leur donnent un nouveau souffle (Neto, Cristina, Lourenço, 2009). Dans certains quartiers menacés, des actions collectives défient les autorités.

6 À partir du cas de la Vila Autódromo, située au cœur de la Barra da Tijuca, je tenterai d'éclairer les modalités et effets de cette résistance localisée. Dès 2010, une partie des résidents, menacée d'évictions par la construction du Parc Olympique, se mobilise contre la destruction de leur quartier. Par sa localisation à proximité d'installations olympiques, mais surtout par cette action collective, le quartier est largement médiatisé et qualifié à de nombreuses reprises de $"$ symbole $»^{6}$ de la lutte contre les 
évictions. Or cette qualification ne va pas de soi : elle est le fruit de pratiques et d'usages sociaux de l'espace dont cet article rend compte pour montrer en quoi l'action collective des habitants de la Vila Autódromo conduit à la production d'un haut lieu de résistance urbaine à Rio de Janeiro.

7 La notion de haut lieu n'est guère employée par les sociologues de l'action collective, qui optent plutôt pour celle de «mobilisations exemplaires» (Péchu, 2002; Mathieu, 2004). L'exemplarité suggère l'efficacité d'un mouvement social à travers des critères tels que l'autonomie, l'ampleur numérique ou la longévité (Hmed, 2007). Néanmoins, les auteurs ne mentionnent pas l'enjeu de l'exemplarité et sa construction délibérée pour «signifier un avenir différent articulé à la désignation d'un problème social » (Micoud, 2010).

8 Les politistes et géographes soulignent dans leurs travaux la capacité des groupes dominés à enrayer la production de la ville néolibérale (Oldield, Stokke, 2004 ; Diétrich 2015 ; Lelandais 2016; Freire, 2018) à travers l'action collective qui vise à la reconnaissance de leurs droits citoyens et citadins. Selon Bayat, la plupart des travaux qui mettent en évidence les résistances des subalternes ont le mérite de souligner l'agentivité des précaires mais écartent les réponses données par les pouvoirs publics et la domination qu'ils exercent sur ces groupes (2013). Selon lui, l'étude des résistances ne peut faire l'économie d'une analyse rigoureuse des relations de pouvoir entre les résistants et les représentants de l'état (notamment à travers l'examen des cooptations). Ainsi, pour ne pas surestimer les résistances locales, il faut examiner les moyens déployés par les représentants de l'État pour désagréger ce haut lieu de l'action collective.

Cette recherche s'appuie essentiellement sur une enquête ethnographique menée au sein de la Vila Autódromo entre février et juin 2015 et qui fut complétée de janvier à juin 2018, après la période d'évictions. A partir d'entretiens compréhensifs, d'observations participantes et d'une immersion de deux mois (voir encadré 1) au domicile d'Inacia, habitante engagée, j'ai pu faire l'expérience du quotidien de la lutte et des effets de la coercition quotidienne exercée par les autorités. A cela s'ajoute la collecte de sources médiatiques et de documents de l'association locale des habitants qui permettent d'envisager le mouvement au-delà de l'enquête de terrain.

\section{Encadré 1 : Conditions d'enquête}

L'enquête de terrain pendant la période d'évictions s'est déroulée entre février et juillet 2015. L'intérêt pour cette favela naît de ma surprise lorsque je remarque, en effectuant des recherches dans des médias brésiliens, que le cas de la Vila Autódromo revient presque systématiquement pour désigner les expulsions, phénomène pourtant généralisé à l'échelle de la ville. Dans le cadre de la réalisation de mon mémoire de $\mathrm{M} 2$, je décide d'analyser les raisons de cette surmédiatisation, en partant de la lutte des habitants. L'essoufflement de la mobilisation, mis en évidence par la diminution du nombre d'habitants mobilisés, me pousse à réorienter mon analyse sur la démobilisation d'une lutte localisée, sujet dont je poursuis l'étude dans mon doctorat.

Mon accès au terrain a été facilité par l'habitude de certains habitants à dialoguer avec des personnes étrangères au quartier, le plus souvent chercheurs, militants ou journalistes. Le séjour chez Inacia, habitante puis amie, simplifia mon 
introduction dans la sphère du voisinage. Les habitants n'ont exprimé aucune méfiance à mon égard. Silencieuse lors des réunions, active lors des protestations, j'ai affiché mon soutien au groupe mobilisé.

Le climat délétère instillé par la municipalité dans le quartier (coupures d'eau et d'électricité fréquentes), ainsi que mes cours à la Fondation Getúlio Vargas me conduisirent à entrecouper mon séjour d'excursions au centre-ville de Rio de Janeiro, à plus de deux heures de transport en commun.

Après deux mois d'immersion, je m'installai au centre-ville et réalisai environ trois fois par semaine des allers-retours vers le quartier.

Dans un premier temps je dresserai une brève sociohistoire de la Vila Autódromo, retraçant les étapes antérieures de la contestation et les interactions entre les pouvoirs publics et l'association des habitants. Puis j'examinerai les pratiques et discours publics utilisés par une partie des résidents pour produire un haut lieu de la résistance. Enfin, je montrerai que malgré la « renommée » du quartier et de ses luttes, la mobilisation est traversée par des conflits et affaiblie par la riposte des pouvoirs publics.

\section{La Vila Autódromo comme enjeu de lutte sociale}

\section{Un espace contesté et contestataire depuis 1993}

\section{Photo ${ }^{\circ} 1$ : La Vila Autódromo}

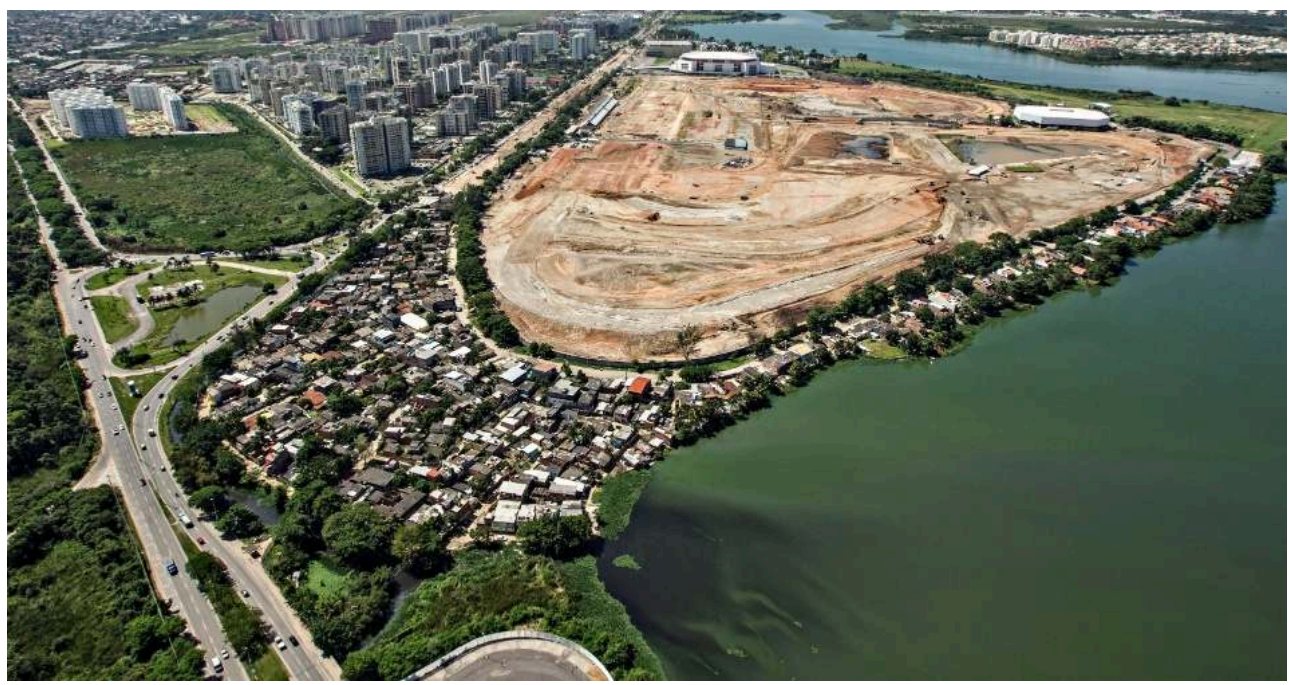

Photo aérienne de la Vila Autódromo (El País Brasil, 2014), enclavée entre les tours de la Barra da Tijuca, l'ancien circuit automobile Nelson Piquet, le lac de Jacarepaguá et l'axe routier Salvador Allende.

11 Dès 1993, les habitants sont menacés d'éviction par une action publique coordonnée par Eduardo Paes ${ }^{7}$, le subprefeito (l'équivalent du maire d'arrondissement) de la zone Ouest de la ville dans laquelle se trouve Barra da Tijuca. En 1995, mobilisés autour de l'association de quartier, ils profitent d'un désaccord politique entre le maire Cesar Maia $(\mathrm{DEM})^{8}$ et le gouverneur Lionel Brizola (PDT) ${ }^{9}$ pour obtenir de ce dernier des concessions de terrain (Concessão de Direito Real de Uso) pour 77 familles, renouvelables 
après 35 ans. En 1998, le gouverneur Marcello Alencar (PSDB) ${ }^{10}$, s'oppose aux menaces d'évictions réitérées par Eduardo Paes et étend la concession à la quasi-totalité des habitants pour une durée de 99 ans (Monteiro, Oliveira, Sanchez, 2016). En 2005, la municipalité déclare une partie du quartier comme Aire Spéciale d'Intérêt Social ${ }^{11}$, ouvrant la voie à une urbanisation future. Cependant, les titres de propriété sont attribués au compte-goutte par les pouvoirs publics, d'abord à la partie considérée comme "favela » (composée de travailleurs pauvres), puis à celle située sur les berges du lac (composée d'habitants exerçant des professions intermédiaires, voir encadré 2). Cette portion du quartier n'a d'ailleurs pas été incluse à l'Aire Spéciale d'Intérêt Social, les berges du lac étant considérées comme "zone à risque ». Cette séparation légale entre les deux espaces (en plus d'être sociale) aura des conséquences sur la mobilisation, les habitants se positionnant distinctement quant à l'issue de la lutte.

Malgré la régularisation du quartier, la municipalité exhorte les habitants à quitter le quartier lors de l'organisation des Jeux Panaméricains prévus pour 2010. Ces derniers obtiennent gain de cause auprès des tribunaux en 2009, mais cela ne décourage pas Eduardo Paes, devenu entre-temps maire de Rio de Janeiro, qui récidive à l'occasion de l'organisation des Jeux Olympiques. En janvier 2010, la municipalité annonce par voie télévisée la destruction de 119 quartiers ${ }^{12}$ pour réaliser de vastes "revitalisations » urbaines.

\section{Encadré 2 : Les habitants de la Vila Autódromo}

En 2010, d'après le recensement réalisé par l'IBGE, la Vila Autódromo est composée de 1252 habitants. 88\% des enfants et adolescents étudient dans les environs et $65 \%$ des habitants travaillent dans un quartier à proximité. 10,6\% des résidents sont locataires de leurs logements, les autres sont tous propriétaires.

Contrairement aux représentations de sens commun, les favelas ne sont pas des espaces homogènes, mais sont fortement stratifiées socialement ${ }^{13}$. Le quartier est ainsi divisé en deux espaces distincts, caractérisés par le type de construction des maisons, leur localisation et le profil économique des habitants :

- La partie située à proximité de la route Salvador Allende et principalement constituée de maisons en briques rouges est majoritairement populaire. De nombreux hommes exercent dans le bâtiment : maçons, charpentiers, électriciens et de quelques pêcheurs. La plupart des femmes sont mères au foyer, femmes de ménage ou secrétaires. D'autres exercent des professions informelles, vendent des cafés et des sucreries dans l'enceinte du quartier.

- Sur les berges du Lac, les habitants vivent dans des maisons plus cossues aux façades peintes, dont certaines sont dotées de piscine. Ils sont économiquement plus aisés que leurs voisins de la partie nord de la favela. Ils exercent des professions libérales, travaillent dans la fonction publique et l'événementiel, ou bien sont en retraite militaire.

À travers les interactions de voisinage et les pratiques quotidiennes de l'espace (Di Méo, 2001), une partie des habitants a construit un fort sentiment d'appartenance à son espace de vie (Frémont, 1999). Certains de ces habitants évoquent avec nostalgie le quartier avant les premières destructions, ils soulignent leur collaboration dans son édification, urbanisé uniquement par leur travail, comme le signale Francisco, âgé de 
plus 50 ans et travailleur dans le BTP : « ma maison et même, ce quartier, c'est toute ma sueur $»^{14}$. Mais aussi Suelly, âgée de 51 ans, femme de ménage qui vit dans le quartier depuis 17 ans dans un logement précaire sans eau courante. Elle dit avoir « tout sacrifié pour transformer cette cabane en maison $»^{15}$. La construction collective du quartier, des rues et des logements par les résidents confère au quartier une charge émotionnelle et des valeurs partagées.

Au cours des entretiens, ces derniers rappellent, non sans émoi, la solidarité et l'entraide, tissées à partir de l'ancrage local. Ces valeurs se manifestent par des pratiques de troc, de transports partagés, de garde d'enfants ou de cagnottes de Noël pour les plus défavorisés. Lors des entretiens, Inacia, chargée du catéchisme et du théâtre et Luis, qui encadre les activités sportives du quartier, m'exposent les photos des nombreuses activités réalisées, notamment avec les enfants et les adolescents. Les habitants s'approprient l'espace à travers la rénovation collective du quartier, les pratiques spatiales quotidiennes. Ils soulignent leur sentiment de sécurité et les relations de confiance tissées au fil des années et affirment qu'ils ne parviendront pas à retrouver dans la ville un espace aussi paisible, idéalement localisé et exempt de violence. Leur résistance contre les évictions a donc aussi pour but de préserver les relations sociales nouées au sein du quartier.

Comme le rapporte Erdi Lelandais dans son étude sur les mobilisations du quartier Vallée de Dikmen à Ankara (2016), le sentiment d'appartenance est renforcé et activé par les menaces de déplacements. La menace sert de déclencheur à la formulation d'une appartenance au quartier. L'espace du quartier et l'habitat, une fois menacés, deviennent inviolables (Mathieu, 2013; Lelandais, 2016). Delmo, âgé de 55 ans, travailleur dans le BTP et ancien militant engagé contre la dictature, proclame avec fermeté sa volonté de rester et me fait part du lien « sacré » qui l'unit à l'espace :

«Je suis ici depuis le début et j'ai un lien très fort avec cet endroit, c'est plus que ma maison tu sais? Tu vois quand un lion choisit une caverne pour élever ses enfants, personne ne peut s'approcher. Eux, parmi un million de cavernes, ils ont choisi la mienne, et à partir de (...) là, elle devient sacrée» ${ }^{16}$.

Cela dit, les individus ne sont pas tous également attachés à leur espace de vie. Cet attachement varie selon l'âge et la durée de résidence: les personnes mobilisées habitent le quartier depuis plus de dix ans, ont plus de 40 ans et sont propriétaires de leur logement. Les locataires, les jeunes adultes, et une grande partie des habitants les plus défavorisés, moins attachés à leur logement ${ }^{17}$, ne participent guère au mouvement de protestation et quitteront le quartier précocement (en 2014).

Pour la plupart des habitants de longue date qui n'ont aucune expérience du militantisme et disposent d'un faible niveau d'instruction, les mobilisations successives (à partir de 1993) forgent leur politisation, marquée par une prise de conscience d'une situation vécue comme injuste. Néanmoins cette politisation est relative et variable selon les trajectoires de vie de chaque habitant. L'exemple d'Altair, président de l'association de quartier depuis 2005, est révélateur de cette politisation par la lutte :

«Je n'ai étudié que jusqu'en sixième. Le temps que j'ai passé dans la lutte, c'est ça qui m'a formé, qui m'a tout appris. Je ne suis pas analphabète parce que j'écris et je lis mais je n'ai pas la culture des personnes de la faculté. Mais peut-être que je comprends plus de choses que certains d'entre eux $»^{18}$.

18 Âgé de 60 ans, il est père de deux enfants et travaille dans un kiosque de la plage de Barra da Tijuca. Sa famille a été évincée de ses précédents logements à deux reprises et subit donc sa troisième menace d'expulsion à Rio de Janeiro. Ces expériences répétées 
de mobilisations contre les évictions consolident ses connaissances à la fois politiques et juridiques. C'est aussi le cas des membres les plus actifs de l'association. Mobilisés depuis 1993, ils témoignent de connaissances solides sur la législation urbaine. La culture politique acquise au cours des luttes successives leur permet d'identifier les interlocuteurs institutionnels et militants et de réactiver rapidement la mobilisation. Les compétences des mobilisés de longue date fonctionnent comme une ressource pour la mobilisation. Elles permettent de retarder les évictions et d'éviter les expulsions sommaires qui ont lieu dans d'autres quartiers cariocas où les habitants, ignorant leurs droits, ont accepté d'être délogés contre de très faibles indemnisations ${ }^{19}$. Dans de nombreux quartiers défavorisés, le sentiment d'incompétence dû aux faibles niveaux d'instruction et de ressources socio-économiques conduisent à une autocensure (Gaxie, 1997) qui entrave l'action collective (Lemanski, 2008). Dans le cas de la Vila Autódromo, c'est grâce à l'association locale et aux soutiens externes au quartier que le savoir et le savoir-faire militant sont transmis à une grande partie des habitants.

\section{L'association de quartier et les soutiens extérieurs comme moteurs de la lutte}

19 Au lendemain du retour à la démocratie (1985), les associations se multiplient au sein des favelas. Les revendications concernent l'implantation d'infrastructures et de services essentiels et, plus largement, le renforcement des instances de représentation des habitants (Goirand, 2001). C'est dans cette effervescence associative que nait, en 1987, l'Association des Habitants et Pêcheurs de la Vila Autódromo (AMPVA). Par son biais, entre 1986 et 1990, les habitants effectuent des travaux d'assainissement et d'accès à l'eau et à l'électricité. En 1993, lorsque surgissent les premières menaces d'évictions, cette rénovation est brutalement stoppée, alors que d'autres favelas bénéficient de programmes d'urbanisation ${ }^{20}$ qui améliorent significativement les conditions de vie (Brum, 2013) ${ }^{21}$. Au contraire la Vila Autódromo porte les marques physiques du désengagement des pouvoirs publics: les rues en terre s'inondent à la moindre pluie, les installations électriques sont précaires, le quartier ne dispose pas de crèche, d'école, ou même de poste de santé.

Dès 1987, l'AMPVA exige à plusieurs reprises de la subprefeitura de Barra da Tijuca et du CEDAE (Compagnie publique d'installation d'eau et d'égout) d'installer le réseau d'eau, le tout-à-l'égout et les infrastructures de base (Vainer, 2013). Mais l'inaction des pouvoirs publics d'abord et l'annonce du démantèlement de la Vila Autódromo ensuite, la poussent à bousculer l'ordre de ses priorités : pourquoi s'efforcerait-elle d'améliorer les conditions de vie du quartier, alors que sa présence même est menacée ? Au cours des années 1990, la lutte en faveur de la légalisation des terrains et contre les évictions devient donc la priorité2 ${ }^{2}$. Elle s'étend sur plusieurs années, au fil des menaces répétées qui s'abattent sur le quartier.

21 Malgré la pression des autorités sur ses présidents successifs, l'AMPVA poursuit la lutte pour le maintien des habitants. La position du président d'association est décisive pour les résidents dans leur choix d'accepter ou non les évictions ${ }^{23}$. En 2010, suite de l'annonce des évictions, ils mobilisent leurs réseaux, constitués lors des précédentes mobilisations, tels que d'autres associations d'habitants et la Pastoral de Favelas ${ }^{24}$, et avertissent les journalistes pour rendre leur action visible. La capacité de l'association à initier des actions protestataires et à les médiatiser s'explique également par l'absence 
de groupes criminels organisé et violents. En effet, ces groupes armés, concurrents des pouvoirs publics et souvent des associations, revendiquent l'appropriation de l'espace, exercent un pouvoir coercitif sur les habitants/militants et les empêchent de mener à bien leur entreprise (Souza, 2006 ; Machado, 2016).

L'enquête de terrain montre que si l'association cible son activité sur les stratégies à mener dans le cadre de la lutte, elle organise aussi de nombreux rassemblements pour consolider les liens de solidarité entre les habitants : repas, fêtes et activités culturelles. Cette ritualisation des moments de convivialité populaire est cruciale (Illich 1975; Melucci 1989; Polletta, Jasper, 2001) puisqu'elle permet de renforcer ou d'inciter l'adhésion des habitants à la lutte. Les réunions de quartier, moments propices de sociabilité, sont organisées chaque mardi soir dans l'église catholique du quartier (les deux églises évangélistes ayant accepté les négociations et quitté les lieux). Plus spacieuse que le local de l'association, l'église permet d'accueillir plus de personnes. L'autel est transformé en tribune d'où les habitants prennent la parole à tour de rôle. C'est également là qu'est stockée une partie du matériel de protestation (banderoles, pancartes, sifflets, casseroles). Après la destruction du local de l'AMPVA, le 24 février 2016, l'ensemble du matériel et des archives y est entreposé25. Ouvert en dehors des offices religieux et accessible aux habitants, l'église fonctionne comme ressource logistique à l'organisation du mouvement social (Ripoll, 2005). Elle est mise à disposition par le prêtre Fabio Freitas, qui a acquis un important leadership en se mobilisant aux côtés des habitants. L'organisation des réunions à l'intérieur même du lieu de culte et le soutien du prêtre, très admiré par les habitants, contribuent au façonnement de la cause, lui conférant une dimension morale.

L'espace de l'église se transforme aussi en lieu de jonction des contestataires. Les réunions sont l'occasion de circulations militante et experte. Elles constituent un moment opportun pour élaborer des stratégies communes et coordonner les actions. Elles rassemblent les résidents les plus actifs à la mobilisation, les adhérents occasionnels qui souhaitent obtenir des informations, les défenseurs publics ${ }^{26}$, des chercheurs et membres d'autres mouvements sociaux urbains. Pastoral de Favelas est représentée par une de ces membres tandis que le Comitê Popular da Copa e das Olimpiadas ${ }^{27}$ est représenté par plusieurs individus, majoritairement des professeurs et étudiants de l'Université Fédérale de Rio de Janeiro, membres des classes moyennes qui disposent de forts capitaux social et culturel. Les soutiens externes apportent un appui numérique, logistique et technique considérable. Ils peuvent toutefois, de façon involontaire, confisquer la parole de certains habitants lors des réunions publiques, en employant un registre de langue soutenu qui intimide. Ces derniers délèguent alors leur parole à ceux qui s'expriment plus facilement.

De plus, la sensation que le quartier est solidement soutenu par des acteurs extérieurs peut aussi relâcher les coûts du désengagement ${ }^{28}$ ressentis par les habitants, qui ont alors moins de scrupules à partir en déléguant leur pouvoir d'action à ces agents considérés comme suffisamment nombreux et expérimentés.

\section{La construction d'un symbole de la lutte contre les évictions}

La Vila Autódromo est fréquemment qualifiée de symbole de la lutte contre les évictions. Mais cette mise en symbole ne va pas de soi. Il importe donc d'analyser ce 
processus de création du symbole, les intérêts des groupes sociaux à le mobiliser et son caractère performatif (Bourdieu, 1982). La construction de " hauts lieux $»^{29}$ de l'action collective a peu été examinée par les sociologues des mouvements sociaux ou les géographes (Ripoll, 2005). Micoud qui étudia le quartier populaire de Monchovet à Saint-Etienne dressa une définition triptyque des hauts lieux, nommés également « lieux construits pour l'exemple », qui fonctionnent s'ils sont à la fois :

« Exemplaires : parce que dignes d'être admirés et de susciter l'adhésion.

Expérimentaux, parce que en même temps lieux à propos desquels sont initiées

d'autres manières de problématiser ce vis-à-vis de quoi ils se présentent comme des solutions.

Exceptionnels, enfin, parce que lieux bénéficiant toujours d'une sorte d'extraterritorialité institutionnelle au motif que ce qui s'y invente demande à être libéré des entraves juridico-administratives ordinaires». (2010:115)

«Comment faire valoir le problème de la désertification rurale, de la fracture sociale des quartiers... sans en montrer des exemples emblématiques?» interroge Micoud. Dans notre cas, la réponse est la même : seule la production d'un haut lieu est à même de signifier et illustrer les déplacements de population à Rio de Janeiro, phénomène abstrait et invisible pour une grande partie des habitants de la ville. Ce passage du lieu (espace quelconque) au haut lieu découle des discours et pratiques des habitants qui sont mis en circulation et repris par d'autres agents.

\section{La Vila Autódromo, construction discursive et circulation d'un exemple}

Du fait de sa localisation dans l'épicentre des constructions du Parc Olympique, ce quartier a concentré l'attention des médias. Alors que de nombreux quartiers populaires sont aussi concernés par les évictions, seules la Vila Autódromo et la Vila do Metrô (située à proximité du stade Maracaña) sont directement menacées par les infrastructures olympiques (Gillon Pascal, 2016). Bien que les deux quartiers subissent la même menace, seule la Vila Autódromo obtient une renommée internationale. Le traitement réservé à la Vila Autódromo s'explique par la construction d'un discours idéalisant, reproduit et diffusé par des soutiens externes au mouvement, qui placent la Vila Autódromo au centre de la lutte contre les évictions à l'échelle de la ville et élèvent le quartier en haut lieu de l'action collective.

En présence des médias ou des fonctionnaires publics, susceptibles d'influencer l'issue de la lutte, les habitants affirment leur légitimité à vivre dans le quartier à partir d'un récit qui l'idéalise. Dans leur discours, ils revendiquent la propriété des biens, l'absence de violence et l'intérêt pour la chose publique. Les enquêtés insistent sur la régularité des terrains possédés : "nous avons les titres de propriété ", "c'est une aire spéciale d'intérêt social ». Ils s'opposent au stigmate construit et véhiculé depuis des décennies par les institutions publiques (Brum, 2013; Magalhães, 2017) et les médias : celui d'envahisseurs de propriétés publiques. Autre image associée aux habitants des favelas, que ces derniers déconstruisent, celle de la violence ${ }^{30}$ : ils rappellent que la Vila Autódromo «est un quartier tranquille», qu'«il n'y a pas de violence ni de groupe armé», « c'est un quartier de travailleurs ». De plus, un panneau placé à l'entrée de la Vila Autódromo indique: "communauté pacifiée et ordonnée depuis 1967». Il contribue à cette mise en récit d'un espace auto-organisé et sans violence, qui ne requerrait pas d'intervention municipale, contrairement à d'autres quartiers où furent 
mises en place des politiques sécuritaires telles que les Unités de Police de Pacification ${ }^{31}$ ou le " choque de ordem $»^{32}$. Les habitants apparaissent unis dans leurs revendications et affirment publiquement leur solidarité, occultant les divisions internes. Les violences et dissensions, inhérentes à chaque quartier (favela ou non), sont minimisées ou mises sous silence. Certains habitants dans les entretiens contredisent ce récit laudatif et affirment que la Vila Autódromo n'est pas exempte de violence, et qu'un président d'association a par ailleurs été assassiné dans les années 1990. Les résidents mettent en évidence leurs expérimentations démocratiques manifestées par leur participation et engagement politique, leurs prises de décisions collectives, locales et mises en pratiques, à l'image du plan d'urbanisme alternatif sur lequel je reviendrai. Sur le mur d'une maison écroulée est tagué le message : « Nous enseignons la démocratie au Brésil, cela ne devrait pas être dans la violence». Dans le même sens, Luis oppose la démocratie brésilienne à leur propre expérience, réprimée par la violence : «La démocratie n'existe pas au Brésil. Quand nous essayons de faire la démocratie, de la pratiquer, nous recevons des balles de caoutchouc au visage, de la violence $»^{33}$.

Avec ces discours, les habitants font du quartier un espace organisé (opposé à l'image de chaos) dont les résidents ont une attitude exemplaire, à contre-courant des stéréotypes sur les favelas, et s'ajustent aux attentes des pouvoirs publics (Goffman, 1975) en se présentant comme des interlocuteurs fiables (Magalhães, 2017). Vraies ou pas, ces représentations, une fois répétées et mises en circulation, valorisent les habitants et font de cette favela un quartier modèle et un exemple à suivre. Ce discours idéalisé est relayé et amplifié par les médias alternatifs et les soutiens externes au quartier. Un des membres du Comitê Popular da Copa m'explique que le mouvement social a centré son attention sur la Vila Autódromo pour le militantisme reconnu de ses habitants et l'absence de groupes armés, ce qui facilite le travail militant sur place et favorise la diffusion d'une image positive et méritante des résidents.

En 2013, le Comitê Popular da Copa e das Olimpíadas érige la Vila Autódromo en symbole de la lutte contre les évictions à l'échelle de la ville à travers le lancement de la campagne "Viva a Vila Autódromo": logos, ouvrages scientifiques et pétitions visent à sensibiliser l'opinion publique au sujet des évictions. Lors des réunions du Comitê, des voix s'élèvent contre cette construction du quartier comme symbole d'un processus généralisé, et expriment la crainte que les luttes d'autres quartiers menacés soient éclipsées (Freire, 2018). Pour les membres favorables à cette mise en valeur, ce choix est avant tout pragmatique : il permet d'illustrer, signifier et nommer un phénomène spatial pouvant être perçu comme abstrait aux yeux des personnes non concernées. Dans le manifeste "Um bairro marcado para viver " ${ }^{34}(2013)$, ils évoquent l'objectif de cette campagne et la volonté de ne pas écarter le quartier d'un processus politique de transformation globale de la ville : « La campagne pour la survie de la Vila Autódromo est une lutte de ses habitants mais également, et surtout, une lutte de tous pour une ville juste et égalitaire ». La mise en symbole participe d'une stratégie des habitants et du mouvement social, en élevant les revendications individuelles, matérialisées, localisées à collectives et politiques, axées sur le droit à la ville, ils opèrent conjointement une montée en généralité des revendications et élargissent l'écho de la lutte.

31 La construction symbolique du quartier a aussi une dimension performative : la désignation de symbole renforce et assoit le caractère exemplaire de l'espace de la Vila Autódromo. Les médias alternatifs ${ }^{35}$ et dominants réutilisent le terme de «symbole » : 
dans un de ces articles, la Rede Globo ${ }^{36}$, disqualifie le quartier en le décrivant comme une " espèce de symbole de la lutte contre les déplacements ${ }^{37}$. Tout en le discréditant, Globo amplifie la dimension symbolique du lieu.

Mais le haut lieu renvoie aussi à une "distinction sociale " (Clerc, 2004) sur d'autres lieux. J'observe la supériorité de la lutte de la Vila Autódromo sur d'autres quartiers également menacés, qui peinent à se frayer une place dans le paysage des mouvements sociaux urbains. Lors d'une audience publique sur le droit au logement à la chambre municipale le 2 juin 2015, à la demande de conseillers municipaux du Parti Socialisme et Liberté ${ }^{38}$ et du Parti des Travailleurs, la position occupée par les représentants de la Vila Autódromo révèle leur supériorité symbolique: alors que les présidents d'associations d'autres quartiers menacés sont dans le public, le prêtre et le président d'association de la Vila Autódromo sont sur l'estrade avec les personnalités politiques. Une mise en scène qui traduit la hiérarchie entre les différents mouvements, la proximité qu'entretiennent les leaders du quartier avec les cadres politiques et donc leur légitimité à s'exprimer prioritairement. La réunion, initialement organisée pour débattre sur le droit au logement, est presque exclusivement consacrée au cas de la Vila Autódromo. Le quartier apparait comme le chef de file de la protestation, chargé de défendre la totalité des quartiers menacés.

\section{Expérimenter l'espace : pratiques et savoirs}

33 Au-delà des discours, les habitants souhaitent mettre en action leurs revendications et faire du quartier un espace de mobilisation citoyenne, faisant converger les luttes pour le droit à la ville. L'essentiel des mobilisations sont concentrées au sein du quartier parce qu'il leur est trop coûteux (en termes financiers et organisationnels) de se rendre massivement au centre-ville, où se tiennent la plupart des protestations sociales, car il est situé à deux heures de transport public, mais aussi parce que le quartier constitue l'enjeu même de la lutte. Les mobilisés parviennent alors à développer la lutte sur place, en faisant venir des alliés influents. D'autres mouvements tels que le Mouvement des travailleurs sans terre, historiquement engagé dans la lutte en milieu rural, le Mouvement des travailleurs sans toits ou le Comitê Popular da Copa e das Olimpíadas, qui dénoncent les effets des grands événements sportifs, rejoignent la lutte dès 2012. En juin, à l'occasion du sommet Rio+20, accompagnés de leaders indigènes, habitants et mouvements sociaux défilent dans le quartier et unissent leur voix contre l'appropriation des terres dans les espaces urbains et ruraux ${ }^{39}$. Cette capacité de mobiliser, sur le lieu même de la lutte, des alliés extérieurs alimente la notoriété de la Vila Autódromo. Malgré un accès restreint aux arènes institutionnelles, les habitants consolident ainsi leurs ressources matérielles et élargissent la médiatisation de leur cause.

Les habitants mobilisés s'appuient sur un répertoire classique de mobilisation, comme l'obstruction temporaire de l'accès au quartier lors de manifestations, à l'aide des matériaux destinés aux travaux du Parc Olympique et aux décombres des maisons déjà démolies (voir photographie ci-dessous). L'isolement du quartier, éloigné aussi bien des condominiums fermés de la Barra da Tijuca que d'autres favelas, conduit les habitants à se rendre visibles sur la route Salvador Allende, dont ils bloquent le trafic à plusieurs reprises. 

organisés par les habitants dans le cadre du festival \#Occupa Vila Autódromo organisé de juillet à août 2015. En s'appropriant les logements détruits pour les transformer en espaces de contestation et en détournant de façon subversive les matériaux destinés à l'édification du Parc Olympique, ils répondent à la détérioration du quartier et aux contraintes matérielles qui leur sont imposées. Le quartier disputé se transforme en arène des rapports de force entre le mouvement social et la municipalité, chacun tentant d'y affirmer son appropriation légitime de l'espace. Néanmoins, la « dispersion des corps » (Ripoll, 2005) au terme des manifestations, réduit la résistance des habitants à une durée limitée, alors que la coercition de la municipalité dans l'enceinte du quartier s'exerce de façon quasi permanente. Pour cette raison, certains habitants réclament l'installation d'un barrage permanent à l'entrée du quartier dans le but de reprendre et exiger le contrôle de l'espace sur une durée prolongée. Ils obtiennent gain de cause après un épisode de violence policière : ils installent un barrage permanent qui filtre l'entrée aux habitants et travailleurs du parc olympique, tout en contrôlant les incursions des forces de l'ordre et des fonctionnaires municipaux.

Blocage temporaire de l'accès au quartier par une partie des habitants de la Vila Autódromo

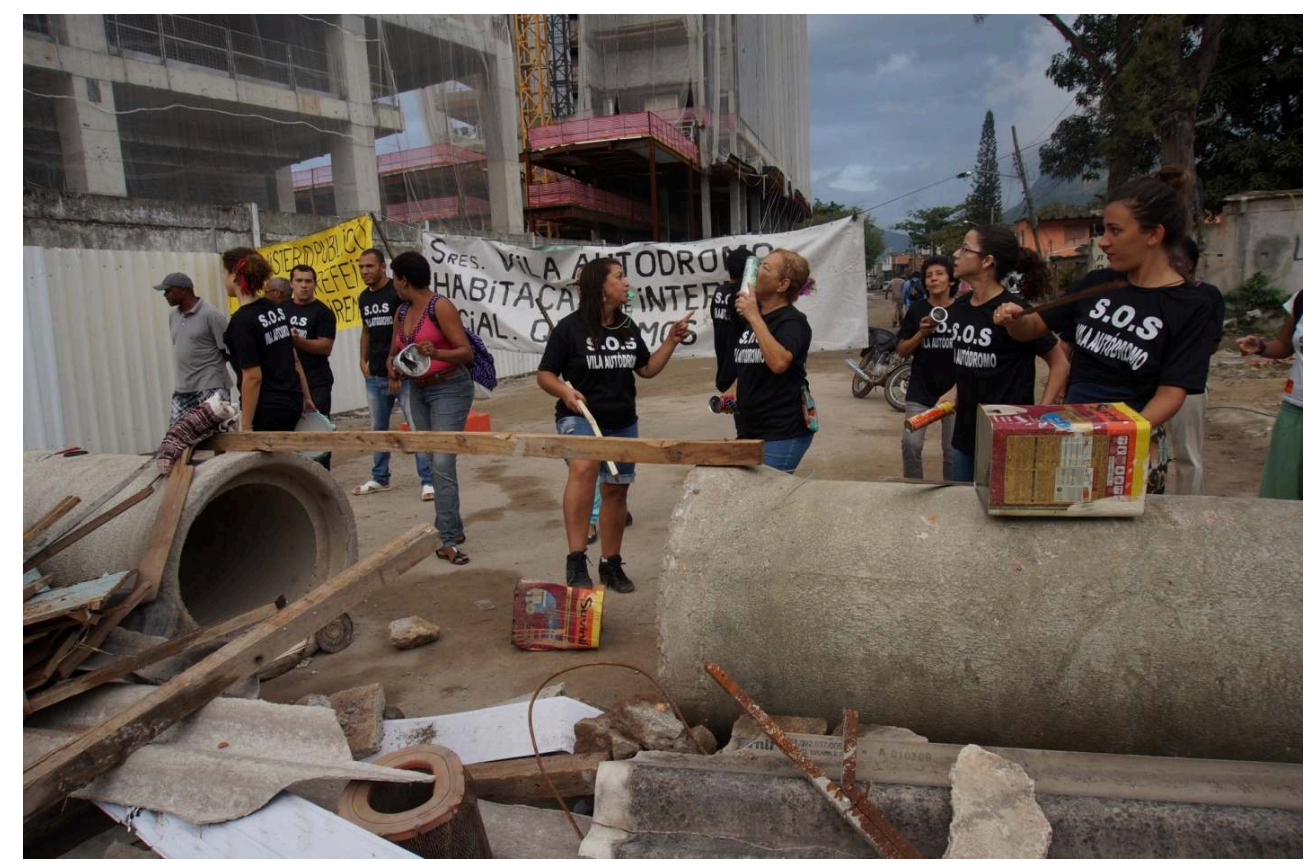

Photo de M. De Barros, mars 2015.

À ces manifestations se mêlent des pratiques de contre-expertise. Des chercheurs influents d'universités publiques apportent leur soutien au mouvement en réalisant, aux côtés des habitants, un plan d'urbanisation alternatif à celui de la municipalité : le Plano Popular da Vila Autódromo. Le recours à la contre-expertise par les mouvements sociaux signifie le rejet et la résistance aux systèmes experts du monde politique qui s'exprime à travers l'usage du même répertoire : la connaissance et la technique. Le plan populaire de la Vila Autódromo est mené par des techniciens, des étudiants et des professeurs en urbanisme (Vainer, Bienenstein, Tanaka, Oliveria, Bobino 2013) issus essentiellement de l'Université Fédérale de Rio de Janeiro et de l'Université Fédérale Fluminense. L'initiative participe aussi à la formation des habitants puisqu'elle compte 
sur la participation active de ces derniers, leurs expériences et leurs connaissances de l'espace vécu, articulées ensuite aux outils techniques déployés par les universitaires.

Ce projet s'oppose au plan de relogement de la municipalité et défend la viabilité des infrastructures du quartier au prix d'une amélioration des services publics. Salué par l'Institut des Architectes Brésiliens ${ }^{40}$ pour son faible coût économique ${ }^{41}$ et ses finalités sociales et écologiques, il remporte en 2015 le prix d'urbanisme Urban Age ${ }^{42}$. Cette victoire légitime encore plus la présence des habitants, offrant une alternative concrète à la destruction de l'espace et la possibilité d'une réalité différente pour les quartiers populaires.

Enfin, le quartier peut être aussi considéré comme «exceptionnel», autre caractéristique d'un haut lieu selon Micoud. La légalité des terrains ainsi que la désignation d'Aire Spéciale d'Intérêt Social confèrent aux habitants une légitimité supplémentaire, actée par le droit. Cette désignation place le quartier dans une position spécifique et avantageuse qui constitue un obstacle à l'éviction des habitants, comme le soulignent à plusieurs reprises les défenseurs publics qui dénoncent l'illégalité des "décrets de désappropriations ». Contrairement à d'autres quartiers où les habitants sont expulsés de façon expéditive, sous prétexte qu'ils ne possèdent pas les biens de propriété occupés, les forces de l'ordre ne peuvent pas, sur le plan légal, agir de la sorte. Les pouvoirs publics sont donc contraints d'employer des moyens également exceptionnels, destinés à désagréger la lutte, sans toutefois tomber totalement dans l'illégalité.

\section{Désagréger le groupe pour faire tomber le symbole}

Les pouvoirs publics, conscients que le quartier a acquis, par la lutte de ses habitants et de leurs soutiens, une importante visibilité, optent pour des moyens de coercition détournés: la répression silencieuse et l'instauration de négociations financières menées dans le but de démobiliser les résidents.

\section{La coercition quotidienne : la spatialité des moyens de contrainte}

Dans le cas des mouvements de quartier, l'analyse des contraintes matérielles pesant sur les agents mobilisés permet de mieux saisir l'individualisation puis le délitement de la lutte, aspects encore peu abordé dans les travaux sur les mouvements sociaux (Fillieule, 2005). Dans certains espaces de contestation moins médiatisés, les forces de l'ordre interviennent brutalement, les maisons sont rasées et les habitants sont déplacés à la périphérie de la ville. Dans le cas de la Vila Autódromo, en dépit d'une position avantageuse au sein de l'espace des mouvements urbains cariocas, les pouvoirs publics viendront à bout de la contestation sociale par des moyens répressifs plus insidieux. Face à ce symbole reconnu nationalement et internationalement, sous la pression du calendrier olympique, la municipalité sape l'effort contestataire en exerçant une violence omniprésente et quotidienne à la fois physique et morale. En dégradant l'habitat et le quartier, les pouvoirs publics favorisent l'émergence d'un climat de tensions pour désolidariser les groupes et détacher peu à peu l'individu de son lieu de vie. La coercition, qui se manifeste par l'ensemble des moyens de contrainte matérielle exercés quotidiennement pour forcer les individus au départ, s'installe 
progressivement et s'intensifie à partir de 2014, lorsque les premières indemnisations sont proposées aux habitants.

En mai 2014, 187 familles (sur 600 environ) souhaitent se maintenir sur place (Monteiro, Oliveira, Sanchez 2016). La violence qui s'exerce sur elles s'incarne dans l'espace du quartier et se traduit par la dégradation des conditions de vie et de l'environnement : fermeture des parcs de jeu et du terrain de football; coupures d'électricité et d'eau ; arbres et espaces verts détruits ; édification d'un mur de taule d'environ deux mètres de hauteur qui épouse les formes du quartier et bloque l'accès aux seuls espaces verts encore disponibles. Frontière matérielle et moyen d'isolement de la population, ce mur est recouvert d'inscriptions taguées : «Droit d'être pauvres, non d'être expulsés », « Nous voulons la justice socio-spatiale ", " Messieurs les juges ne laissez pas la justice devenir un théâtre de marionnettes, la démocratie est malade ». Par ailleurs la tranquillité et le sentiment de sécurité des habitants sont mis à mal par la présence de 3000 travailleurs du Parc Olympique qui traversent le quartier pour se rendre au travail. Les maisons des familles qui ont négocié leur départ avec la municipalité sont partiellement détruites et, comme dans d'autres favelas, les décombres, délibérément laissées sur place, dégradent l'espace de vie et exercent une pression psychologique sur ceux qui restent. Les moustiques sont devenus un véritable enfer pour les habitants et les visiteurs. Déjà présents à cause de la proximité du lac de Jacarapaguá, ils prolifèrent avec la présence des décombres à ciel ouvert et perturbent le quotidien. Plusieurs enquêtés ayant quitté les lieux attribuent partiellement leur départ à la prolifération de ces nuisibles qui limitent le déplacement dans les rues une fois le soir tombé et affectent le sommeil. Il n'est pas rare d'entendre parler de difficultés respiratoires dues à la poussière produite par les travaux à proximité et le stress ou d'accidents cardio-vasculaires. Beaucoup d'habitants évoquent leur manque de sommeil, la dépression et le renfermement sur soi. Ainsi, la coercition s'exerce par l'intermédiaire de l'espace matériel, se répercute sur les corps fatigués et la santé mentale, contraignant les habitants les plus récalcitrants à négocier. Si l'on ajoute des intimidations, la présence d'agents de police aux entrées et sorties du quartier, et des incendies même peut-être ${ }^{43}$, on voit que la mairie ne lésine pas sur les moyens de contrainte.

41 Le processus de déplacements est sur toutes les lèvres et rythme l'essentiel des discussions entre voisins (Magalhães, 2017). Pour une partie des habitants, quitter le quartier pour aller travailler est devenu impossible. Ils craignent une démolition arbitraire et restent confinés chez eux. D'autres, qui travaillent dans le bâtiment, ne peuvent tout simplement plus exercer leur métier puisque les matériaux de construction sont confisqués par la police municipale placée à l'entrée du quartier. La municipalité, en contraignant les mobilités, retient les habitants dans un quartier dégradé et les confine à l'intérieur de l'espace domestique. Afin de mieux leur faire assimiler la future disparition du quartier, les adresses des habitants sont rendues invalides par les pouvoirs municipaux et les agents de poste ne distribuent plus leur courrier. Inalva, habitante depuis plus de vingt ans dans le quartier, s'exprime en ces termes :

« Nous passons de la situation d'une communauté qui dispose de titres, qui est reconnue et identifiée à la situation d'une communauté abandonnée, invisible, qui n'a pas d'identification. Nous, nous n'existons plus, tout est en train d'être démoli et il ne reste plus que quelques personnes" ${ }^{44}$. 
42 la perte de ces repères conduit à une sensation d'impuissance et de dissolution de l'identité personnelle. De même, les formes de routine spatiale (Auyero, 2005), qui jouent un rôle moteur dans la consolidation des liens entre habitants, sont affectées. En effet, les lieux du quotidien tels que la boulangerie, le bar, le supermarché, les deux églises évangéliques, négocient avec la municipalité leur départ contre dédommagements et sont fermés, contraignant les habitants à se déplacer à l'extérieur pour pourvoir à leurs besoins. Les menaces d'expulsions se répercutent sur le travail, atteignent l'espace de vie et portent un coup à leur sentiment d'appartenance, à l'espace et au groupe.

\section{Le fractionnement de la lutte par les promesses du relogement}

Parallèlement à la coercition, la municipalité met en place sa stratégie d'atomisation des habitants (Bayat, 1997), en proposant un programme de relogement. Comme pour d'autres favelas soumises à une entreprise d'éviction, elle dispose d'un puissant outil de persuasion: l'édification d'un parc de logements destiné aux habitants de la Vila Autódromo, le Parque Carioca. La construction de ces logements sociaux coïncide avec le développement du programme social Minha Casa Minha Vida (MCMV) ${ }^{45}$. Lancé en mars 2009, ce programme permet à des familles à faibles revenus ${ }^{46}$ d'accéder à la propriété privée moyennant le paiement d'un faible loyer. Officiellement destiné à améliorer les conditions d'existence des plus défavorisés, MCMV joue un rôle clé dans la relégation des populations indésirables aux marges de la ville (Faulhaber, Azevedo 2015 ; Marques, Rodrigues, 2013). En dépit de l'engagement du gouvernement de privilégier des solutions de relogement à proximité, les populations déplacées sont pour la plupart reléguées à la périphérie des villes, loin des lieux de travail, de loisirs et de sociabilité (à l'instar des habitants de la Vila do Metrô relogés à $62 \mathrm{~km}$ du centre, à Santa Cruz). À l'inverse, le Parque Carioca, où la municipalité entend reloger les habitants de la Vila Autódromo, se situe à seulement deux kilomètres. L'argument d'une relative proximité spatiale est avancé pour persuader les moins engagés à quitter le quartier.

En octobre 2013, la municipalité lance son opération séduction : des agents municipaux du Service Municipal de l'Habitat organisent une visite guidée du Parque Carioca. Grâce à la mise en scène d'un habitat de luxe avec surveillance, piscine et toboggans, la municipalité pousse les habitants à se désolidariser du mouvement et du quartier. En même temps, lors d'une réunion organisée au centre des congrès Riocentro ${ }^{47}$, le maire promet la présence permanente d'un service de sécurité privé, des techniciensréparateurs et la prise en charge du déménagement. De plus, il garantit aux habitants la possibilité d'obtenir le titre de propriété du logement, ce qui leur permettrait de louer ou revendre le bien à leur guise (Williamson 2018). En leur offrant l'accès à la propriété légale des biens et une échappatoire à leurs conditions de favelados, la municipalité stimule leur désir d'ascension sociale.

La visite guidée et les engagements pris par le maire sont déterminants pour faire vaciller les indécis. Ces derniers développent un imaginaire positif autour de ce nouvel espace, et projettent la possibilité d'une vie en dehors de la Vila Autódromo. Un premier groupe d'habitants défavorisés, récemment installés dans la Vila Autódromo ou peu engagés lors des mobilisations antérieures contre les déplacements, quitte ainsi le quartier en 2014 (Williamson, 2018). Il est suivi en 2015 par un deuxième groupe 
d'habitants qui ne supportent plus la coercition des autorités et renonce à la lutte ${ }^{48}$. Mais les promesses du maire ne sont pas tenues et les habitants du Parque Carioca déchantent rapidement ${ }^{49}$ : le parc de logements (à l'instar de nombreux logements MCMV) est enclavé et isolé, les services basiques (éducation, transport, santé) y sont absents, les activités économiques informelles (communes à la Vila Autódromo) y sont interdites. En 2018, lors d'une enquête menée au sein du Parque Carioca, j'ai observé que certains logements étaient en état d'insalubrité (fuites d'eau, affaissement du sol, installation électrique précaire), et que les infrastructures de loisirs, espaces verts et piscine, étaient hors de fonctionnement. De plus le quartier est contrôlé par la milice, ce qui crée un sentiment d'insécurité chez bon nombre d'habitants.

\section{Exacerbation des conflits internes et essoufflement de la mobilisation}

Les actions coercitives des pouvoirs publics et la multiplication des départs affectent l'atmosphère du quartier et portent un coup aux sociabilités locales. Cependant, un noyau dur de militants constitué principalement d'individus vivant depuis plus de vingt ans dans le quartier poursuit la résistance. Pour désagréger ces dernières solidarités, la municipalité redouble d'effort et met en place une habile stratégie pécuniaire semant la discorde : les sommes proposées pour quitter le quartier varient d'un habitant à l'autre et suscitent la convoitise. Elles atteignent dans certains cas des montants très élevés, inégalés dans l'histoire des déplacements forcés au Brésil : jusqu'à 3,395 millions de reais, environ 970000 euros, en juin $2015^{50}$.

Une des tactiques employées par les pouvoirs publics est d'accentuer la distance sociale entre les habitants les plus aisés du quartier, dont l'espace de vie est limité aux rives du lac, et les habitants les plus défavorisés, regroupés près de l'avenue Salvador Allende. Les premiers disposent d'un capital politique et économique majeur, qui leur permet de mieux négocier avec la municipalité. Malgré leur proximité géographique, les deux groupes, aux caractéristiques socioéconomiques différentes, sont divisés quant à l'attitude à adopter face aux évictions. La proximité sociale prime sur la proximité spatiale ou, ici, l'appartenance à un même quartier. Comme le rappelle Bourdieu, « on est ainsi conduit à mettre en doute la croyance que le rapprochement spatial d'agents éloignés dans l'espace social peut, par soi, avoir un effet de rapprochement social (...) En fait, rien n'est plus intolérable que la proximité physique (vécue comme promiscuité) de gens socialement éloignés » (1993 : 166). Les dissensions entre les deux groupes sociaux s'exacerbent lorsque les habitants de la partie défavorisée constatent que la mairie propose à ceux des berges du lac des compensations financières bien plus importantes. Ces derniers, au contraire, s'estiment lésés par l'action du président d'association et jugent qu'il défend uniquement le maintien des habitants de la partie considérée comme favela. Lors d'un entretien, Alexandre, 37 ans, professeur de samba et habitant des berges du lac, exprime son ressentiment :

«Nous avons beaucoup manqué de communication dans ce processus mais surtout de solidarité. Parce qu'ici il y a eu une division entre les personnes du lac et les personnes d'en bas, et nous nous avons été exclus parce qu'il a été dit, même par le président d'association, que nous n'avions besoin de rien et que nous voulions tous négocier.». 
De plus, le départ de ménages aisés, issus des berges du lac, incite parfois au départ des habitants plus modestes, tel que Jorge, pêcheur et travailleur dans le bâtiment de 54 ans :

« Je sentais que ça allait se terminer. Quand les démolitions ont commencé, les grandões (habitants aisés) se sont rendus. Les grandões c'étaient le colonel et la clique qui vivaient près du lac. Ça n'allait pas être la classe ouvrière qui était en bas qui allait rester, j'en avais la certitude. $»^{51}$

Dans le même temps, les résidents doutent des objectifs de la lutte et des stratégies collectives. Craignant d'être totalement dépossédés, ils optent peu à peu pour des recours individuels en justice ou négocient avec les pouvoirs publics en parallèle du combat qu'ils mènent. Un soir, j'accompagne deux habitantes pour photographier discrètement les maisons de familles ayant négocié leur bien en échange d'indemnisations élevées. Photographies à l'appui, elles souhaitent négocier favorablement leur sortie. Malgré leur activité militante en faveur du maintien du quartier, elles ne croient plus à une issue favorable de la lutte et élaborent des stratégies de sortie. Au printemps 2015 , lors d'une réunion à l'église, le prêtre constate la situation ambivalente de nombreux habitants et les incite «à se remobiliser et à affirmer une position ferme ». Les divergences et les doutes fragilisent la poursuite de la lutte et la met dans une position d'entre-deux qu'il juge intenable. Les alliés externes exhortent également les habitants à se mobiliser mais sont impuissants face à la multiplication des défections. Celles-ci sont d'autant plus dures à prévenir qu'elles se produisent en silence : les habitants qui jettent l'éponge n'osent pas affronter le regard de leurs voisins, qui considèrent le départ comme une trahison. Les discours des alliés externes ne persuadent plus une partie des résidents, comme Inacia le souligne lors d'une conversation informelle: «eux ne vivent pas ici, c'est facile de nous forcer à continuer la lutte sans même subir ce qu'on vit au quotidien ".

Les luttes pour le leadership enveniment également la situation et des conflits éclatent entre groupes d'habitants et membres de l'association. Les stratégies de division de la municipalité portent leurs fruits. En 2015, le président de l'association, qui dénonçait les «tentatives de coup d'état» et déplorait l'inaction des habitants, déclare: «malheureusement, la résistance s'éteint $»^{52}$. En retrait lors des mobilisations observées, à cause de désaccords avec les mobilisés, il négocie finalement son départ pour la somme de 1,4 millions de réais ${ }^{53}$, et quitte le quartier en août 2015. L'individualisation des propositions de relogement comme tactique des pouvoirs publics (Talpin, 2016) enraye la mobilisation et le départ du leader légitime la négociation individuelle au détriment de l'action collective.

Les positions divergentes à l'intérieur d'un même foyer conduisent parfois à des conflits entre ses membres, voire à l'implosion du cercle familial : c'est le cas ubuesque d'un habitant, divorcé, qui constate à son retour du travail que sa maison est scindée en deux, laissant les pièces ouvertes sur la rue et exposées à la vue de tous, puisque son exfemme a accepté l'indemnisation municipale de sa moitié du logement. Pour d'autres, le foyer, déjà affecté par les menaces de désappropriations et la dégradation des conditions de vie, devient l'ultime espace à protéger. Une fois le sentiment d'appartenance entamé par la destruction du quartier et des solidarités locales, beaucoup d'habitants se replient sur les liens familiaux et tentent de les préserver. Inacia, qui habite le quartier depuis 30 ans, décide ainsi de taire son engagement à son mari qui souhaite partir et n'approuve pas «l'acharnement» de sa femme : elle quitte le quartier en juin 2015 pour « sauver son couple $»^{54}$. A contrario, quelques familles unies 
dans leurs revendications rejettent toute forme de négociation avec la municipalité à l'image de celle de Maria da Penha. Âgée de 51 ans, femme au foyer et catholique pratiquante proche du prêtre Fabio de Freitas, Maria da Penha vit dans la Vila Autódromo depuis 22 ans. Elle devient une figure de la lutte à la suite de violences policières dont elle est victime le 3 juin 2015. Son mari Luis et sa fille Natalia sont mobilisés à ces côtés. Comme dans d'autres collectifs militants, la solidarité familiale favorise ici le maintien de l'engagement politique (Passy, 1998) :

«La famille est très importante, elle doit être unie et savoir ce qu'elle veut (...) quand le jeune ou la femme ne veulent pas rester, c'est compliqué. C'est ce qui s'est passé ici avec la plupart des familles qui se sont divisées, et il fallait qu'ils trouvent un équilibre, ils devaient donc partir, et ils devaient perdre. Notre famille, ma fille et mon mari, nous en sommes venus à la conclusion que nous allions rester et lutter ensemble $»^{55}$.

51 Après le départ du président d'association, Maria da Penha le remplace informellement et poursuit la lutte en faveur du maintien. En 2016, année de l'organisation des JO, les soutiens externes au mouvement affluent dans le quartier et se regroupent autour de sa figure, comblant ainsi l'absence des habitants partis. Lors de la démolition de son logement, le 8 mars 2016, plus de 50 personnes extérieures au quartier sont présentes pour la soutenir. En plus des défenseurs publics, de membres du Comitê Popular da Copa et de Pastoral de Favelas, elle reçoit aussi le soutien de mouvements féministes pour la Journée Internationale des droits des femmes.

52 L'appui de mouvements extérieurs sauvegarde et alimente la visibilité du quartier. Ce même jour, la municipalité annonce l'urbanisation du quartier pour les vingt dernières familles ayant refusé de négocier. Transformée en grande partie en parc de stationnement, la Vila Autódromo ne désigne plus qu'une seule rue composée de vingt maisonnettes blanches alignées et identiques. Seule l'église catholique a été préservée. La présence des habitants reste précaire puisqu'ils ne possèdent pas les titres de propriété de leurs logements. La menace d'une éviction future plane toujours.

\section{Conclusion}

53 Le cas de la Vila Autódromo, dont l'histoire sociale est façonnée par ses luttes, apparait comme singulier à Rio de Janeiro. Grâce à l'effort collectif des habitants relayé par des agents externes, le quartier se transforme en « aimant » et « repère » (Clerc, 2004) de la mobilisation contre les expulsions à l'échelle de la ville. La démobilisation visible de la majorité des habitants n'affecta pas, et c'est surprenant, la renommée du quartier, confirmant la force des représentations qui produisirent le haut lieu et la reconnaissance dont jouissent les derniers militants.

Malgré la spécificité du lieu, ces analyses conduisent également à étendre notre regard sur les modes selon lesquels l'action collective opère dans les quartiers populaires. Marginalisés socialement, leurs habitants doivent le plus souvent redoubler d'efforts pour gommer ou retourner le stigmate qui leur est apposé et faire valoir leurs revendications comme légitimes. Leur précarité est souvent instrumentalisée par les pouvoirs publics qui tantôt criminalisent l'action collective et répriment les habitants, tantôt tentent de les coopter en leur faisant miroiter la possibilité d'un avenir meilleur par des contributions financières ou par l'accès à un emploi. Même si la plupart des mobilisations demeurent fragiles, instables et soumises à de fortes pressions, elles 
permettent une mise à l'agenda des problèmes publics (ici les déplacements) et forgent les compétences et la culture politique des résidents.

La dispersion des habitants laisse penser qu'une fois relogés ou indemnisés, une grande partie d'entre eux se détourne de l'action collective. Si certains se retirent totalement, d'autres, à l'image d'Inalva ou Altair, réactivent leur savoir-faire au sein d'autres espaces militants, comme le Comitê Popular da Copa ou d'autres quartiers menacés de déplacements. La circulation de ces anciens habitants dans d'autres espaces militants ainsi que le maintien de vingt familles sont le produit des pratiques et expériences politiques de la Vila Autódromo. Toute lutte populaire, quelle que soit son issue, produit des effets, inspire et montre la voie à d'autres qui lui succèderont.

\section{BIBLIOGRAPHY}

ABREU M. (1987), A evolução urbana do Rio de Janeiro, Rio de Janeiro, IPLANRIO, Zahar, 147 p.

AUTHIER JY., BAQUET MH., GUERIN-PACE (2007), Le quartier : enjeux scientifiques, actions politiques et pratiques sociales, Paris, Éditions de la Découverte, $394 \mathrm{p}$.

AUGUSTIN JP. (2009), « Les Jeux Olympiques, l'événement spatial par excellence », Bulletin de l'Association de géographes français, 86, 3, pp. 303-311.

AUYERO J. (2005), «L'espace des luttes : Topographie des mobilisations collectives », Actes de la recherche en sciences sociales, $\mathrm{n}^{\circ} 160$, pp. 122-132.

BAYAT A. (1997), Street Politics, Poor people's movement in Iran, Colombia Press University, 256 p.

-- (2000), « From Dangerous Classes' to 'Quiet Rebels': Politics of the Urban Subaltern in the Global South », International Sociology, vol. 15, no. 3, pp. 533-557.

BLOT J., SPIRE A., (2013), « Les déplacements forcés dans les villes du Sud : les déguerpissements en question ", L'Espace politique, $\mathrm{n}^{\circ} 22$, en ligne.

BORJA J., CASTELS M. (1998), Local y global. La gestión de las ciudades en la era de la información, Mexico, Santillana Ediciones, 277 p.

BOURDIEU P. (1982), Ce que parler veut dire : l'économie des échanges linguistiques, Paris, Fayard, 243 p.

-__ (1993), La misère du monde, Paris, Éditions du Seuil, 1472 p.

BRUM M. (2012), Cidade Alta, histórias e memorias da remoção e a construção do estigma da favela num conjunto habitacional, Rio de Janeiro, Ponteio Edição, 437 p.

(2013), « Favelas e remocionismo ontem e hoje : da Ditadura de 1964 aos Grandes Eventos », O social em questão, n'29, pp. 179-208.

CARVALHO B, CAVALCANTI C, VENUTURUPALLI R. (2016), Occupy All Streets: Olympic Urbanism and Contested Futures in Rio de Janeiro, Rio de Janeiro, Terreform, 216 p.

CLERC P. (2004), « Haut Lieu », Hypergéo, en ligne. 
COMBES H., GARIBAY C., GOIRAND.C (2016), Les lieux de la colère : occuper l'espace pour contester, de Madrid à Sanaa, Paris, Karthala, $410 \mathrm{p}$.

COSSART P. TALPIN J. (2015), Lutte urbaine: Participation et démocratie d'interpellation à l'Alma Gare, Éditions du croquant, coll. « Sociopo », Vulaines-sur-Seine, 408 p.

DAHLET P. (2016), « Quand la favela devient comunidade : nomination et contrôle social », Argumentation et analyse du discours, $\mathrm{n}^{\circ} 17$, en ligne.

DEBARBIEUX B. (1993), « Du haut lieu en général et du mont Blanc en particulier ». L'Espace géographique, $\mathrm{n}^{\circ} 24, \mathrm{pp}$. 5-13.

-_- (1995), « Le lieu, le territoire et trois figures de rhétorique ». Espace géographique, n²2-1, pp. 97-112.

DI MEO G. (2001), Géographie sociale et territoires, Paris, Nathan Université, ? 317p.

-_- (2002) « L'identité: une médiation essentielle du rapport espace/société », Géocarrefour, $\mathrm{n}^{\circ} 77-2$, pp. 175-184.

DIETRICH J. (2015), « Contestation ou négociation à Jakarta? Deux quartiers face aux projets urbains de la métropole », Cybergeo : European Journal of Geography, en ligne.

ERDI LELANDAIS G. (2016), « Le quartier comme espace de résistance et de politisation », Cultures \& Conflits, $\mathrm{n}^{\circ} 101$, pp. 139-167.

FAULHABER L. AZEVEDO L. (2015), SMH 2016: remoções no Rio de Janeiro Olímpico, Rio de Janeiro, Mórula Editorial, $112 \mathrm{p}$.

FILLIEULE O. (2005), Le désengagement militant, Paris, Belin, coll. « Sociologiquement », 319 p.

FREMONT A. (1999), La région, espace vécu, Paris, Flammarion, 288 p.

GAXIE D. (1978), Le cens caché, Inégalités culturelles et ségrégation politique, Paris, Seuil, 267 p.

GILLON P. (2016), « Les Jeux Olympiques de Rio 2016 : un héritage mais au profit de qui ?», Géoconfluences, en ligne.

GOFFMAN E. (1975), Stigmate. Les usages sociaux des handicaps, Paris, Éditions de Minuit,180 p.

GOIRAND C. (2001), La politique des favelas. Paris, Recherches internationales, Karthala, 273 p.

HMED C. (2007), « Contester une institution dans le cas d'une mobilisation improbable : La "grève des loyers" dans les foyers Sonacotra dans les années 1970. » Sociétés contemporaines, Paris, Presses de Sciences Po, pp. 55-81.

-_- (2008), « Des mouvements sociaux "sur une tête d'épingle” ? Le rôle de l'espace physique dans le processus contestataire à partir de l'exemple des mobilisations dans les foyers de travailleurs migrants ", Politix, n 84 , pp.145-165.

HARVEY D. (2011). Le capitalisme contre le droit à la ville : néolibéralisme, urbanisation, résistances. Paris, Editions Amsterdam, 96 p.

-_- (2016), Rebel cities: from the right to the city to the urban revolution, Editions Verso, New York, 208 p.

HUCHZERMEYER M. (2011), Cities With 'Slums': From Slum Eradication to a Right to the City in Africa, Cape Town, University of Cape Town Press, 296 p.

ILLICH I. (1975), La convivencialidad, Barcelone, Barral, 198 p. 
LEMANSKI C. (2008), Houses without community: problems of community (in)capacity in Cape Town, South Africa, Environment and Urbanization, n²0, pp. 393-410.

LUNA FREIRE F. (2017), « « Les Jeux Olympiques pour qui ?» Les actions du Comité Populaire de la Coupe du monde et des Jeux Olympiques de Rio de Janeiro contre un modèle urbain d'exclusion ». Problèmes d'Amérique latine, $n^{\circ} 4$, pp.95-117.

MACHADO DA SILVA L.A. (1967), « A política na favela », Cadernos Brasileiros, n4, pp.699-716

-_- (2010), « "Violência urbana”, segurança pública e favelas: o caso do Rio de Janeiro atual ». Caderno CRH n²3, pp. 283-300.

(2016), Fazendo a cidade: trabalho, moradia e vida local entre as camadas populares urbanas. Coleção Engrenagens urbanas. Rio de Janeiro, Mórula Editorial, 362pp.

MAGALHÃES A. (2013), Transformações no problema favela e a reatualização do problema da remoção de favelas no Rio de Janeiro, Thèse de doctorat en anthropologie sociale, Université de Lisbonne et Université d'État de Rio de Janeiro, 323 p.

MARQUES E, RODRIGUES L. (2013), « O Programa Minha Casa Minha Vida na metrópole paulistana: atendimento habitacional e padrões de segregação ». Revista Brasileira de Estudos Urbanos e Regionais, $\mathrm{n}^{\circ} 2$, pp-159-177.

MATHIEU L. (2001), Mobilisations de prostituées, Paris, Sociohistoires, Belin, 333p.

MATHIEU L. (2002), « Rapport au politique, dimensions cognitives et perspectives pragmatiques dans l'analyse des mouvements sociaux ", Revue française de science politique, n², pp. 75-100.

MC ADAM D, TARROW S, TILLY C. (2001), Dynamics of Contention, New York, Cambridge University Press, $387 \mathrm{p}$.

MELUCCI A. (1989), « Getting involved: identity and mobilization in social movements ». In From structure to action: comparing social movement research across cultures, Greenwich, International social movement research, $358 \mathrm{p}$.

MERKLEN D. (2009), Quartiers populaires, quartiers politiques, Paris, La Dispute, 304 p.

-- , PLAYERS G. (2011), La localisation des mouvements sociaux, Cahiers des Amériques Latines, n66, pp. 25-37.

MICOUD A. (1991), « Des hauts lieux : la construction sociale de l'exemplarité ». Éditions du CNRS, $133 \mathrm{p}$.

-_- (2010), "Le lieu comme figure exemplaire de l'ordre du territoire qui vient", Communications, Autour du lieu, pp. 109-119.

MONTEIRO P., DE OLIVEIRA F., SANCHEZ F. (2016), « Vila Autódromo em disputa : sujeitos, instrumentos e estratégias para a reinvenção do espaço », Revista Brasileira de Estudos Urbanos, Recife, vol. 18, n³, pp. 408-427.

NETO SL., MELLO PIMENTO L. (2009), « A favela ainda não venceu, mas continua lutando. Movimentos sociais de moradores de favela no Rio de Janeiro. » OPSIS, vol. 9, n¹3, pp. 136-151.

NINNIN J. (2014), «Le rêve carioca : entre planification urbaine et déplacements forcés de population ». L'Espace Politique. Revue en ligne de géographie politique et de géopolitique, $n^{\circ} 22$, en ligne.

OBSERVATORIO DAS METROPOLES (2015), Rio de Janeiro: os impactos da Copa do Mundo 2014 e das Olimpíadas 2016, Rio de Janeiro, Letra Capital Editora, 170 p. 
PASSY F. (1998), L'action altruiste : contraintes et opportunités de l'engagement dans les mouvements sociaux, Genève, Droz, $270 \mathrm{p}$.

POLLETA F., JASPER J. (2001), « Collective Identity and Social Movements ». Annual Review of Sociology, pp. 283-305.

PÉCHU C. (2002), Les mouvements immigrés, dans La France rebelle. Tous les foyers, mouvements et acteurs de la contestation, Paris, Michalon, pp. 471-482.

RIPOLL F. (2004), « L'appropriation de l'espace au regard des mouvements sociaux contemporains : quelques réflexions sur les enjeux, modalités et ressources de l'action ». ESO Travaux et Documents, Espaces et SOciétés - UMR 6590, pp. 45-50.

RIPOLL F. (2005), « S'approprier l'espace... ou contester son appropriation ? », Norois, 195, pp. 29-42.

- - (2006), « Du rôle de l'espace » aux théories de « l'acteur » (aller-retour) : La géographie à l'épreuve des mouvements sociaux ", dans Penser et faire la géographie sociale: Contribution à une épistémologie de la géographie sociale. Presses universitaires de Rennes, en ligne.

-_- (2008), « Espaces et stratégies de résistance: répertoires d'action collective dans la France contemporaine ", Espaces et sociétés, n¹34, pp. 83-97.

SANTOS MAIA R. (1998), « A produção do espaço em áreas de auto segregação: o caso da Barra da Tijuca », Anuário do Instituto de Geociências, UFRJ, vol. 21, pp. 39-75.

SANTOS JUNIOR O, NOAVES R.P. (2017), « Rio de Janeiro ville Olympique: les impacts territoriaux d'un ajustement spatial néolibéral », Problèmes d’Amérique Latine, n¹04, pp. 121-142.

SOARES R.G (2016), « Les favelas de Rio de Janeiro : informalité urbaine et droit à la ville », Paris, Tous urbains, $\mathrm{n}^{\circ} 15$, pp. $45-48$.

SOUZA M J. L. (2001), Mudar a cidade: uma introdução crítica ao planejamento e à gestão urbanos. Rio de Janeiro, Bertrand Brasil, $556 \mathrm{p}$.

SOUZA M J. L. (2006), « Social Movements as ‘Critical Urban Planning Agents ». City, pp. 327-342.

TALPIN J. (2016), « Une répression à bas bruit. Comment les élus étouffent les mobilisations dans les quartiers populaires », Métropolitiques, en ligne.

TILLY C. (1986), La France conteste: de 1600 à nos jours. Paris, L'espace du politique, Fayard, 622 p.

VAINER C. (2013), « Cidade de Exceção: reflexões a partir do Rio de Janeiro », Cadernos do IPPUR, en ligne.

-_- «O plano popular da Vila Autódromo, uma experiência de panejamento conflitual », Documento da conferência ANPUR, en ligne.

VALLADARES L. (2006), La favela d'un siècle à l'autre, Paris, Éditions de la maison des sciences de l'homme, $229 \mathrm{p}$.

WILLIAMSON T. (2018), “Nem todos tem um preço”, RioOnWatch, en ligne.

ZALUAR A, ALVITO M. (1998), Um século de favela, Rio de Janeiro, FGV Editora, 204 p. 


\section{NOTES}

1. Données du recensement réalisé par l'IBGE (Institut Brésilien de Géographie et Statistiques) en 2010. A l'échelle de Rio de Janeiro les favelas concentrent 23\% de la population, 1,443 million d'habitants.

2. Bus Rapid Transit, bus ayant ses propres couloirs, construits de 2010 à 2016 .

3. Carvalho Hosken, promoteur immobilier qui, aux côtés des entreprises Odebrecht et Andrade Gutierrez (consortium RioMais), a construit le Parc Olympique dans le cadre d'un partenariat public-privé et qui possède plus de 10 millions de $\mathrm{m}^{2}$ de Barra da Tijuca, n'a jamais caché sa volonté de transformation du quartier, selon lui « destiné à l'élite ».

4. A Rio de Janeiro, ces évictions sont concomitantes à l'installation de polices de pacification dans des favelas à fort potentiel touristiques (Vidigal, Cantagalo ou Santa Marta) ou ayant une renommée internationale (Cidade de Deus). S'en suit une tendance, plus ou moins effective et marquée selon les lieux, à la gentrification, manifestée par une hausse des prix de l'immobilier, des loyers et du coût de la vie conduisant à la mobilité contrainte de populations défavorisées au profit d'individus aux revenus supérieurs (Ninnin 2013; Quirion 2017 ; Santos Junior, Ramos Novaes, 2017).

5. Le «favelado », considéré par les pouvoirs publics comme « envahisseur de terrains publics », transgresse les normes sociales basées sur la propriété individuelle. Voir Brum, 2012.

6. C'est le cas de plusieurs médias internationaux : «Une petite favela résiste à son déplacement en vue des JO », Le point éd. électronique, 21 août 2012 ; GATINOIS C. « JO 2016 : Vila Autódromo et ses rebelles des jeux ", Le monde, éd. électronique), 16 juin 2016 ; GRIFFIN G. " Change beckons for Vila Autódromo, the favela that got in the Rio Olympic's way », The Guardian, éd. éléctronique, 26 avril 2016. Des chercheurs la désignent également comme symbole, voir : Brum 2012 ; Poliana 2016 ; Neto 2018 ; Magalhães, 2017.

7. Affilié au Parti du Mouvement Démocratique Brésilien (PMDB). Parti de centre-droit.

8. Affilié au parti Democratas. Parti conservateur de centre-droit.

9. Affilié au Parti Démocratique des Travailleurs (PDT). Parti de centre-gauche.

10. Affilié au Parti Social Démocrate Brésilien (PSDB). Parti libéral de centre-droit, principal opposant au Parti des Travailleurs (PT).

11. Art 77 et 78 de la loi sur les Áreas de Especial Interesse Social (AEIS) : « Les AIES permettent que les lotissements irréguliers, qui sont aujourd'hui considérés clandestins et irréguliers soient mieux intégrés à la ville ».

12. O'Globo : "Prefeitura removerá 119 favelas até o fim de 2012", 7/01/2010

13. Luiz Antonio Machado da Silva qualifie les couches supérieures de "bourgeoisie favelada ", composée essentiellement d'individus au fort capital social et politique.

14. Conversation informelle, 18 mars 2015.

15. Idem.

16. Entretien au domicile, 26 avril 2015.

17. Entretiens réalisés en 2018 au Parque Carioca, où furent relogés une partie des habitants.

18. Entretien au domicile, 10 Juin 2015.

19. Certaines familles ont quitté le quartier avec des sommes d'argent dérisoires. Voir Tapley

E.« Resumo das Remoções no Rio Olímpico », Journal en ligne RioOnWatch, 20/08/2012

20. Au Brésil, urbanização désigne la réhabilitation des favelas. Comme le souligne Rafael Soares Gonçalves, ce terme rappelle implicitement que la favela n'intègre pas la ville «avant d'être atteinte par les travaux publics de réhabilitation" alors même qu'elles sont largement consolidées (2016).

21. Le Programa de Urbanizaçao de Assentamentos Populares do Rio de Janeiro, connu sous le nom de Favela-Bairro, est lancé en 1993. L'objectif est d'intégrer davantage les favelas à la ville en y développant les infrastructures urbaines, les équipements publics et les politiques sociales. 
22. Entretien avec le président de l'AMPVA, à son domicile, 10 Juin 2015.

23. Le cas de la Vila União de Curicica, quartier de Rio de Janeiro le plus affecté par le processus d'évictions (950 familles), est un contre-exemple pertinent : en 2014, le président de l'association de quartier est coopté par les pouvoirs publics et incite les habitants à accepter les indemnisations. Robinson, accompagné d'autres habitants défendant le maintien, crée une association dissidente mais celle-ci, par son caractère informel, est illégitime aux yeux des pouvoirs publics. De plus, ses membres ont perdu un temps précieux dans la structuration du mouvement et l'élaboration des stratégies à mettre en place. (À partir de propos recueillis lors d'une réunion organisée à la Vila União par le Comitê Popular da Copa).

24. Organisation catholique créée en 1977 pour défendre le droit au logement.

25. Luís Claudio da Silva «A Igreja católica São José Operário inserida na luta da Vila Autódromo ", museudasremocoes.com, avril 2018

26. Les défenseurs publics sont des avocats chargés de défendre les intérêts des populations défavorisées. Ils sont rattachés à la Defensória Pública, institution publique qui assiste juridiquement et gratuitement les particuliers disposant de faibles ressources financières. Les défenseurs publics chargés de défendre les habitants de la Vila Autódromo sont regroupés au sein du Núcleo de Terras e Habitação (NUTH). Ils accompagnent les politiques publiques du logement et interviennent en cas de conflits d'usage.

27. Organisation créée à l'occasion de la Coupe du monde de football 2014 pour dénoncer les effets des méga-événements sur la ville.

28. Plusieurs contraintes limitent le désengagement militant et individuel dans le quartier, parmi elles : la crainte d'être taxé de traitre, l'attachement au quartier, les rétributions du militantisme : prestige, reconnaissance etc. (Gaxie, 2005).

29. Notion francophone traduite par "espaço simbólico" en portugais et "symbolic space» en anglais.

30. Dès les années 1990, la construction du problème de la «violence urbaine » passe par la désignation des habitants des favelas comme responsables de l'augmentation des délits et des crimes. À partir de 2004 (après des conflits entre groupes armés de la favela Rocinha), la lutte contre la violence justifie certaines expulsions menées par les pouvoirs publics tandis que l'association entre la figure du bandit et habitants de la favela est renforcée.

31. Police de proximité implantée dans certaines favelas pour démanteler le crime organisé.

32. Opérations policières brutales et non planifiées menées dans des «espaces d'insécurité publiques propices aux crimes", qui touchent de nombreux quartiers précaires et individus vulnérables, toxicomanes et vendeurs informels, dont le but est de «mettre fin au désordre urbain » (www.rio.gov.br, 2009).

33. Entretien au domicile, mars 2018

34. Disponible sur le blog de Raquel Rolnick, chercheuse à l'Université de São Paulo: https:// raquelrolnik.wordpress.com/tag/copa-do-mundo-2014/

35. Principalement les journaux en ligne Mídia Ninja et RioOnWatch.

36. Premier groupe médiatique brésilien.

37. O Globo: "Moradores pedem para sair da Vila Autódromo", 30/10/2013, (http:// oglobo.globo.com/rio/moradores-pedem-para-sair-da-vila-autodromo-1-10607952)

38. Parti d'extrême gauche né en 2004 d'une scission du PT.

39. «Índios e movimentos sociais reforçam protesto contra desocupação de Vila para Obras das Olímpiadas», Amazonia.org.br, 21/06/2012.

40. «Comparação vê projeto popular para Vila Autódromo como mais adequado», O Globo, 26/08/2013.

41. 13 millions de réais, environ 2,8 millions d'euros. 
42. Le concours Urban Age est organisé chaque année par la Deutsche Bank en association avec la London School of Economics and Political Science. Selon ses fondateurs : «ce prix se concentre sur les projets dont bénéficient les communautés locales et leurs résidents et qui participent à l'amélioration de leur environnement », (https://www.ædb.com/cr/en/concrete-urbanage.html).

43. L'origine des incendies reste inconnue. En Juin 2015, les habitants accusent les pouvoirs publics d'avoir provoqué un départ de feu. Un habitant m'a également signalé avoir incendié un tracteur en guise de protestation.

44. Observation d'une réunion à l'église de la Vila Autódromo le 26 mars 2015.

45. Ce programme est coordonné par le Secrétariat Municipal de l'Habitat, et géré financièrement par la Caixa Economica Fédéral.

46. Ayant un revenu brut maximal de 7000 reais par mois (http://www.caixa.gov.br/voce/ habitacao/minha-casa-minha-vida/urbana/Paginas/default.aspx).

47. Réunion de présentation du projet d'urbanisation à une partie des habitants de la Vila Autódromo. O Dia « Eduardo Paes hostilizado no Riocentro », 7/10/2013.

48. Au total 341 familles ont été relogées au Parque Carioca.

49. Après trois ans dans ces logements, beaucoup d'entre eux pensent avoir été dupés par le maire. Depuis 2015, en constatant la dégradation de leurs conditions vie et les indemnisations reçues par les habitants qui avaient tardé à accepter les conditions de leur relogement, plus de cent familles ont décidé d'attaquer en justice la municipalité, la Caixa Economica Federal, et le constructeur immobilier (Consortium RioMais) pour dommages moraux.

50. Au total, 220 millions de réais ont été versés aux habitants indemnisés, soit 17 fois le montant du Plano Popular da Vila Autódromo proposé par les universitaires de l'UERJ et de la UFF. Voir Mariah de Queiroz: "Removidos pelo parque Olímpico, lutam por compensação mais justa », Publica, 20/02/2017.

51. Entretien au domicile, 17 mars 2018.

52. Entretien au domicile, 10 Juin 2015.

53. One man, one city, three evictions, Thomson Reuters Foundation, Vidéo Youtube, 24/04/2017

54. Conversation informelle, mai 2015.

55. Entretien au domicile, février 2018.

\section{ABSTRACTS}

From 2010 to 2016, some of the inhabitants of Vila Autódromo- a neighborhood in Rio de Janeiro threatened by the evictions linked to the construction of the new Olympic Park - got mobilized against the destruction of their living space. By analyzing the discourses, practices and experiences of space produced by some residents and conveyed by the media and external social movements, we seek to understand how residents managed to turn the area into a "symbolic space" of urban resistance in Rio de Janeiro and to temporarily establish a balance of power with the municipality. Taking into consideration the neighborhood's reputation, the authorities first refrained from brutality and arbitrary repression - unlike in other favelas - and rather used more insidious means. They proposed material and financial negotiations on an individual basis - 
which divided the inhabitants - and used daily coercion in order to break up local solidarity and exhaust the inhabitants, encouraging them to leave.

De 2010 à 2016, une partie des habitants de la Vila Autódromo, quartier de Rio de Janeiro menacé d'évictions par le nouveau Parc Olympique en construction, se mobilise contre la destruction de leur lieu de vie. À travers l'examen des discours, pratiques et expériences de l'espace produits par une partie des résidents puis véhiculés ensuite par les médias et des groupes issus de mouvements sociaux externes, nous cherchons à comprendre comment les habitants parviennent à ériger le quartier en «haut lieu» de la résistance urbaine à Rio de Janeiro et à imposer temporairement un rapport de force à la municipalité. Prenant en considération la renommée du quartier, les pouvoirs publics s'abstiennent d'abord de réprimer brutalement et expéditivement la contestation comme dans d'autres favelas, mais usent de moyens plus insidieux. Ils proposent à titre individuel des négociations matérielles et financières qui divisent les habitants et emploient quotidiennement la coercition dans le but de désagréger les solidarités locales et d'épuiser les habitants, les encourageant in fine à précipiter leur départ.

\section{INDEX}

Mots-clés: évictions, mouvement de quartier, haut lieu, Rio de Janeiro

Keywords: evictions, urban social movement, symbolic space, Rio de Janeiro

\section{AUTHOR}

\section{MARGAUX DE BARROS}

Doctorante FNRS en Sciences politiques, Centre d'Études de la Vie Politique, Université libre de Bruxelles

Margaux.de.barros@ulb.ac.be 